\title{
INFLUÊNCIA DE FUNGOS MICORRÍZICOS ARBUSCULARES NO DESENVOLVIMENTO DE PLANTAS DE ALECRIM E MANJERICÃO
}

\author{
O.M.R. Russomanno ${ }^{1 *}$, P.C. Kruppa ${ }^{1}$, M.T.A. Minhoni ${ }^{2}$
}

${ }^{1}$ Instituto Biológico, Centro de Pesquisa e Desenvolvimento de Sanidade Vegetal, Av. Cons. Rodrigues Alves, 1252, CEP 04014-002, São Paulo, SP, Brasil. E-mail: russomano@biologico.sp.gov.br

\section{RESUMO}

\begin{abstract}
O objetivo do presente trabalho foi avaliar a influência dos fungos micorrízicos arbusculares Glomus etunicatum Becker \& Gerd. eGlomus clarum Nicol. \& Schenck, no desenvolvimento de plantas de alecrim (Rosmarinusofficinalis L.) e manjericão (Ocimum basilicumL.) inoculadas, separadamente, em condições controladas. Utilizou-se substrato autoclavado composto por uma parte de areia e uma de terra; o inóculo constou de esporos [500 esporos de G. etunicatum ( $\left.50 \mathrm{~mL}^{-1}\right)$ de solo e 700 esporos de G. clarum $\left(50 \mathrm{~mL}^{-1}\right)$ de solo] e ainda fragmentos de raízes infectadas e micélio. Em cada tipo de planta inoculada foram avaliados: altura das plantas (AP), peso da matéria seca da parte aérea (MSPA), peso da matéria fresca das raízes (MFR), esporulação (E) e colonização radicular (CR). O delineamento experimental foi inteiramente casualizado com três tratamentos (GE G.etunicatum; GC -G.clarume T - Testemunha), 16 repetições para o alecrim e 12 para o manjericão. Cada parcela foi representada por um vaso, contendo uma planta para o alecrim e três para o manjericão. No alecrim, G. clarum mostrou-se mais eficiente do que G. etunicatumem $\operatorname{AP}(24,15 \%)$, MSPA (67,16\%) e E (48,16\%); por outro lado, G. clarum apresentou CR menor do que G.etunicatum. Em relação às plantas testemunha, $G$. clarum diferiu destas em todas as variáveis analisadas, porém G. etunicatum nãodiferiu das plantas testemunha em APeMSPA. No manjericão, em relação a todas as variáveis analisadas, G. clarum diferiu da testemunha e de G. etunicatume, este, foi semelhante ao tratamento controle em todas as variáveis, excetopara CR e E. Comparado ao controle, G. clarum proporcionou ao manjericão aumentos de 45,49\% em AP e 93,10\% em MSPA.
\end{abstract}

PALAVRAS-CHAVE: Fungos micorrízicos arbusculares, Rosmarinus officinalis , Ocimum basilicum,FMA.

\section{ABSTRACT}

INFLUENCE OF ARBUSCULAR MYCORRHIZAL FUNGI ON ROSEMARY (ROSMARINUS OFFICINALIS L.) AND BASIL (OCIMUM BASILICUM L.) PLANTS. The aim of this research was to evaluate the influence of AMF Glomus etunicatum Becker \& Gerd. and Glomus clarum Nicol. \& Schenck on rosemary (Rosmarinus officinalis L.) and basil (Ocimum basilicum L.) plants previously inoculated in the greenhouse. The soil was sterilized and composed of one part sand and one part earth. The inoculum was composed of the fungi spores [ 500 spores of G. etunicatumin $\left(50 \mathrm{~mL}^{-1}\right)$ soil and 700 spores of G. clarum in $\left(50 \mathrm{~mL}^{-1}\right)$ soil] and micelium and roots fragments infected by the AMF. For each plant inoculated an evaluation was made of: plant height (PH), plant dry weight (PDW), root fresh weight (RFW), sporulation (S) and the mycorrhizal colonization (MC). The experiment was carried out in a completely randomized factorial design with three treatments (GE G.etunicatum; GC-G.clarum; T-control), with 16 replicates for rosemary and 12 replicates for basil. In the rosemary, G. clarum was more efficient than G. etunicatumin the variables PH( $24.15 \%)$, PDW $(67.16 \%)$ and S (48.16\%); although G. clarum presented a smaller MC than G. etunicatum. In relation to the control, G. clarum was better for the plants in regard to all the variables, although G. etunicatum did not differ for the control plants in PH and PDW. For basil in all the analised variables G. clarum differed from control and from G. etunicatum, which was similar to the control treatment in all the variables, except in the MC and S. In relation to the control, G. clarum was better for the basil in regard to PH (45.49\%) and PDW (93.10\%).

KEY WORDS: Arbuscular mycorrhizal fungi, Rosmarinus officinalis, Ocimum basilicum, AMF.

\footnotetext{
${ }^{2}$ Universidade Estadual Paulista, Faculdade de Ciências Agronômicas, Departamento de Produção Vegetal, Setor de Defesa Fitossanitária, Botucatu, SP, Brasil.

*Parte da tese de doutorado defendida por Olga M. R. Russomanno, no Departamento de Produção Vegetal, Setor de Defesa Fitossanitária, Faculdade de Ciências Agronômicas, UNESP, em maio de 2006.
} 


\section{INTRODUÇÃO}

O alecrim (Rosmarinus officinalis L.) e o manjericão (Ocimum basilicum L.) são plantas medicinais e condimentares da família Lamiaceae, empregadas comumente na medicina caseira e na gastronomia para o preparo de diversos alimentos. Os fungos micorrízicos arbusculares (FMA), pertencentes à ordem Glomales (Glomeromycota), estabelecem uma simbiose mutualista coma maioria das plantas terrestres. A colonização ocorre no sistema radicular destas e resulta em aumento na absorção de nutrientes do solo, principalmente do fósforo, dentre outros fatores. São também conhecidos como fungos endomicorrízicos, pois ao serem inoculados no hospedeiro, penetram o córtex das raízes e diferenciamse em estruturas intracelulares especiais denominadas arbúsculos (AlLen, 1991). Os efeitos benéficos da inoculação dos FMA sobre o crescimento enutrição de plantas de interesse econômico são bastante acentuados e de grande interesse ecológico e comercial (Zambolim ; Siqueira, 1985; Siqueira, 1986). Os FMA crescem em associação com a planta e ramificam-se no solo, além das raízes, atuando como complemento do sistema radicular do hospedeiro e isto aumenta a capacidade de absorção em locais não atingíveis pelas radicelas. Portanto, as plantas colonizadas pelos FMA são capazes de utilizar nutrientes que ocorrem em quantidades "limitantes" no solo, reduzindo, desta forma, as deficiências. Além disso, diversas pesquisas têm demonstrado que esses fungos estão associados a aumentos no desenvolvimento das plantas, aumentos na absorção deágua e resistência das plantas a períodos de estiagem e, principalmente, aumentos na resistência das plantas a patógenos do sistema radicular, principalmente fungos (Аввоtт; Robson, 1984; Powell; Bagyaraj, 1984; Paula; Siqueira, 1987; Silveira, 1992; Smith; Read, 1997).

Os efeitos benéficos dos FMA têm sido demonstrados em variadas condições e espécies vegetais, estimulando o crescimento vegetal como uma conseqüência de seu efeito na nutrição mineral da planta (Antoniolli;KAMinski, 1991; SMith;ReAd, 1997; BResSAN et al., 2001). Entretanto, pouco se conhece sobre os efeitos dos FMA sobre o crescimento e produção das plantas medicinais, condimentares earomáticas. Com o intuito de pesquisar a produtividade da espécie hospedeira, CAMPRUBi et al. (1991) estudaram o efeito da inoculação de quatro plantas medicinais (Salvia officinalis L., Artemísia dracunculus L., Thymus vulgaris L. e Ocimum basilicum L.) com o FMA Glomus mosseae (Nicol. \& Gerd.) Gerd \& Trappe e obtiveram, em todas as espécies, maiores pesos secos das raízes e das plantas, comparado com as plantas controle não inoculadas. Nesse mesmo contexto, estudando a in- fluência do FMA Glomus deserticola Trappe, Bloss \& Menge sobre o crescimento deRosmarinusofficinalis L., sobre condições de estresse hídrico (14 dias),SANCHEZBLANCO et al. (2004) demonstraram haver aumento na biomassa aérea e radicular das plantas micorrizadas, quando comparadas às testemunhas. Alguns destes trabalhos estão associados à produção equalidade de óleos essenciais por estes tipos de plantas, quando inoculadas com FMA (KAPOOR et al., 2002a,b; GuPTA et al., 2002; FREITAS et al., 2004).

O cultivo de plantas medicinais, condimentares e aromáticas é de importância fundamental para a humanidade, pois, além de serem utilizadas pela medicina como fitoterápicos, em substituição aos medicamentos sintéticos, apresentam teores elevados de óleos essenciais utilizados nas indústrias de cosméticos e perfumarias. Além disso, muitas destas plantas servem de condimentos para o preparo de diferentes tipos de alimentos, nos mais diversos países, inclusive no Brasil. Diante disso, o presente trabalho teve como objetivo estudar a influência dos FMA Glomus etunicatum eGlomusclarum sobre o desenvolvimento de plantas de alecrim e de manjericão.

\section{MATERIAL E MÉTODOS}

O presente trabalho foi realizado em condições de laboratório com temperatura e luz controladas, no Laboratório de Micologia Fitopatológica, Centro de Pesquisa e Desenvolvimento de Sanidade Vegetal, Instituto Biológico de São Paulo. Tanto para a produção do inóculo como para a realização dos experimentos, a temperatura do laboratório foi mantida entre 26 $\pm 2^{\circ} \mathrm{C}$, mediante o auxílio de um aparelho de ar condicionado. A intensidadeluminosa durante estas duas fases foi obtida pela luminosidade proveniente da luz do dia, equivalendo a, aproximadamente, 13 horas de luz e 11 horas de ausência de luminosidade.

$\mathrm{O}$ delineamento experimental foi inteiramente casualizado com três tratamentos (GE- Glomus etunicatum Becker \& Gerd.; GC-Glomus clarum Nicol. \& Schenck; T- testemunha, sem inoculação), 16 repetições para o alecrim (Rosmarinus officinalis L.) e 12 repetições para o manjericão (Ocimum basilicum L.). Cada repetição foi representada por um vaso, contendo uma planta para o alecrim e 3 plantas para o manjericão. Os dados foram submetidos à análise de variância para experimentos inteiramente casualizados, empregando-se os testes F e Tukey no nível de $5 \%$ de probabilidade. Para efeito de análise, os dados relativos à colonização micorrízica foram transformados para arco seno $\sqrt{x / 100}$ e a contagem de esporos para $\sqrt{x+0,5}$ (SNEDECOR; COCHRAN, 1972). As demais variáveis foram analisadas com os dados originais. 
O solo utilizado foi composto de amostra $(0-20 \mathrm{~cm})$ coletada de um Latossolo Vermelho Escuro textura média(CARvalHo et al., 1983), na Fazenda Experimental Lageado, Botucatu (SP). A seguir, a amostra foi seca ao ar e peneirada em malha de 2,00 mm ea análise química (macroemicronutrientes)foifeitaconformemetodologia de RAI et al. (2001), no Laboratório de Fertilidade doSolo do Departamento de Ciências do Solo, Faculdade de Ciências Agronômicas, UNESP, Botucatu, SP, apresentando as seguintes características: $\mathrm{pH}$ em $\mathrm{CaCl}_{2}, 4,0$; matéria orgânica $(\mathrm{MO}), 10,00 \mathrm{~g} / \mathrm{dm}^{3} ;$ Presina, 2,00 mg/ $\mathrm{dm}^{3} ; \mathrm{K}, 0,20 \mathrm{mmol}_{\mathrm{c}} / \mathrm{dm}^{3} ; \mathrm{Ca}, 1,00 \mathrm{mmol}_{\mathrm{c}} / \mathrm{dm}^{3} ; \mathrm{Mg}, 0,02$ $\mathrm{mmol}_{\mathrm{c}} / \mathrm{dm}^{3} ; \mathrm{Cu}, 1,20 \mathrm{mg} / \mathrm{dm}^{3} ; \mathrm{Fe}, 76,00 \mathrm{mg} / \mathrm{dm}^{3} ; \mathrm{Mn}$, $0,30 \mathrm{mg} / \mathrm{dm}^{3} ; \mathrm{Zn}, 0,20 \mathrm{mg} / \mathrm{dm}^{3} ; \mathrm{SB}, 1,00 \mathrm{mmol}_{\mathrm{c}} / \mathrm{dm}^{3}$; CTC, $69,00 \mathrm{mmol}_{\mathrm{c}} / \mathrm{dm}^{3} \mathrm{e} \mathrm{V}, 2,00 \%$.

O substrato utilizado nos experimentos foi uma mistura de solo e areia de rio lavada, na proporção de 1:1 (v/v), esterilizado pelo processo de tindalização, em autoclave sob vapor fluente, temperatura de 90 a $100^{\circ} \mathrm{C}$, durante duas horas, por três dias consecutivos. A seguir o substrato foi seco em estufa a $50^{\circ} \mathrm{C}, \mathrm{com}$ ventilação, revolvendo-o de hora em hora para auxiliar na secagem.

Os fungos micorrízicos arbusculares (FMA) utilizados(G.etunicatume G. clarum), provenientes daESALQ - USP, foram multiplicados sobre plantas de sorgo (Sorghum bicolor L.) cultivar Rubi. Cada inóculo de FMA constou de esporos [500 esporos deG.etunicatum $(50 \mathrm{~mL})^{-1}$ de solo e 700 esporos de G.clarum $(50 \mathrm{~mL})^{-1}$ de solo] e ainda fragmentos de raízes infectadas e micélio, constituindo uma mistura de solo contendo esporos, hifas e fragmentos de raízes colonizadas.

Para o alecrim foram utilizadas mudas obtidas por estaquia, previamente enraizadas em areia de rio lavada, sem adubação, durante 60 dias em casa de vegetação. Em vasos plásticos com capacidade para $550 \mathrm{~mL}$, foram adicionados $350 \mathrm{~mL}$ de substrato e, sobre este, $50 \mathrm{~mL}$ de inóculo do respectivo endófito, plantando-se a seguir a muda de alecrim e completando-se o volume do vaso com o restante do substrato até $500 \mathrm{~mL}$ de sua capacidade. Foram inoculados 16 vasos com G.etunicatum e 16 com G.clarum. O mesmo procedimento foi utilizado para as plantas testemunha, com igual número de repetições, porém, estas não receberam inóculo de FMA. Para o manjericão empregaramse sementes comerciais não tratadas que passaram por processo prévio de desinfestação em solução $0,5 \%$ de hipoclorito de sódio por 15 minutos. Em vasos plásticos com capacidade para $550 \mathrm{~mL}$, foram adicionados $400 \mathrm{~mL}$ de substrato, depositando-se sobre este, a seguir, dez sementes de manjericão em cada vaso, cobrindo- as com fina camada do substrato, ou seja, 50 $\mathrm{mL}$. Foram inoculados 12 vasos com G. etunicatum 12 com G. clarum. O mesmo procedimento foi utilizado para as plantas testemunha, com igual número de repetições. Cada um dos vasos testemunha recebeu 450
$\mathrm{mL}$ de substrato e, sobre este, foram semeadas dez sementes de manjericão, cobrindo-as com mais $50 \mathrm{~mL}$ do substrato. Trinta dias após a germinação das sementes, procedeu-seodesbaste, mantendo-setrês plantas por vaso, tanto para as plantas inoculadas com FMA quanto para as plantas testemunha. Tanto para o alecrim quanto para o manjericão, cada vaso recebeu $50 \mathrm{~mL}$ de solução diluída (1:1000) de alguns macronutrientes após a inoculação dos FMA, de 15 em 15 dias, até o final do experimento. Em cada vaso foi adicionado um total de $24,8 \mu \mathrm{g}$. $\mathrm{g}^{-1}$ de fósforo. As soluções estoques $1 \mathrm{M}$ dos macronutrientes utilizados foram: sulfato de magnésio - $\mathrm{MgSO}_{4}\left(120 \mathrm{~g}\right.$. $\left.\mathrm{L}^{-1}\right)$; nitrato de potássio $-\mathrm{KNO}_{3}\left(101 \mathrm{~g} . \mathrm{L}^{-1}\right)$; fosfato de potássio $\mathrm{KH}_{2} \mathrm{PO}_{4}\left(136 \mathrm{~g} . \mathrm{L}^{-1}\right)$; nitrato de cálcio - $\mathrm{Ca}\left(\mathrm{NO}_{3}\right)_{2}(164 \mathrm{~g}$. $\left.\mathrm{L}^{-1}\right)$. De cada uma dessas soluções estoques foi retirado $1 \mathrm{~mL}$, completando-se o volume para $1.000 \mathrm{~mL}$ com água destilada. Solução diluída (1:1000) de micronutrientes, de Hoagland \& Arnon, descrita por SARRUGE (1975), sem o manganês, também foi adicionada a cada 15 dias, intercalada com a solução de macronutrientes, até o final do experimento, na quantidade de $50 \mathrm{~mL}$ por vaso. Os vasos testemunhas foram adubados da mesma forma que os inoculados com os FMA. A umidade dos vasos foi mantida em torno de $60 \%$ da capacidade de campo.

As variáveis relativas ao crescimento e micorrização das plantas foram determinadas aos 120 dias após o plantio ou semeadura. As variáveis analisadas foram: altura das plantas (AP); matéria seca da parte aérea (MSPA); matéria fresca das raízes (MFR); taxa de esporulação (E) e porcentagem de colonização micorrízica (CR). Para a contagem dos esporos, as plantas de cada vaso foram cortadas rente ao solo, eliminando-se a parte aérea e reservando-se a porção contendo solo e raízes; essas raízes foram cortadas em pedaços de $1 \mathrm{~cm}$ de comprimento e devolvidas ao substrato. Uma porção desse substrato (cerca de $50 \mathrm{~mL}$ ) foi reservada para a contagem dos esporos de G. etunicatum e G. clarum, através da técnica de peneiramento do solo em via úmida e decantação, segundo GERDEMANN; Nicolson (1963), e centrifugação em sacarose, segundo JENKINs (1964). A quantificação da colonização micorrízica foi realizada empregando-se os métodos de coloração de raízes e porcentagem de colonização micorrízica descritos, respectivamente, por Phillips; Hayman (1970) e GiovanNnEtTi; Mosse (1980). A altura das plantas foi determinada a partir de meio centímetro da superfície do solo. Para o alecrim, o resultado foi oriundo de apenas uma planta por vaso (16 repetições), enquanto que, para o manjericão, o resultado foi uma média das três plantas por vaso (12 repetições). Para a determinação da matéria seca da parte aérea, as plantas foram cortadas a 0,5 cm da superfície do solo, lavadas (água corrente, destilada e deionizada), acondicionadas em sacos de 
papel e deixadas para secar em estufa a $60^{\circ}$ Catéobterse peso constante. Em seguida, determinou-se o peso da matéria seca em balança de precisão. Para a determinação da matéria fresca das raízes em balança de precisão, estas foram previamente lavadas em água corrente e ligeiramente secas em papel absorvente comum.

\section{RESULTADOS E DISCUSSÃO}

Os efeitos da micorrização nas plantas de alecrim são apresentados na Tabela 1. A altura (AP), matéria seca da parte aérea (MSPA) e esporulação (E) foram maiores nas plantas inoculadas com G. clarum em relação às inoculadas com G. etunicatum, ou seja, $24,15 \%, 67,16 \%$ e $48,16 \%$, respectivamente para AP, MSPA e E. Entretanto, para a colonização radicular (CR) ocorreu o inverso, ou seja, foi maior em 30,89\% nas plantas inoculadas com G. etunicatum. Para a variável MFR, não houve diferença em relação à espécie de FMA inoculado, que foi de 1,14 g/vaso paraG. clarum e 0,94g/vaso paraG. etunicatum. Quando comparado a G. etunicatum $(85,21 \%)$, pode-seobservarque G. clarum $(65,10 \%)$ apresentou menor colonização radicular, porém maior esporulação, ou seja, 254,1 esporos de G.clarum $(50 \mathrm{~mL})^{-1}$ de solo e 171,50 esporos de G. etunicatum $(50 \mathrm{~mL})^{-1}$ de solo. Em relação às plantas testemunha, G. clarum diferiu destas em todas as variáveis, a presentando valores de $25,93 \%, 42,55 \%$ e 51,35\%, respectivamente para AP, MFRe MSPA. Por outro lado, G. etunicatum não diferiu das plantas testemunha nas variáveis AP e MSPA.

Apesar de G. etunicatum apresentar maior colonização radicular (CR) que G. clarum, ou seja, 85,21\% contra $65,10 \%$, isto não foi refletido na variável altura (AP) que foi $24,15 \%$ maior para G. clarum quando comparado a G. etunicatum. O aumento da colonização micorrízica parece nem sempre se correlacionar com o aumento do crescimento da planta, como demonstrado em trabalhos que revelam a ocorrência de uma grande variabilidade na capacidade do FMA em colonizar as raízes do hospedeiro (infectividade) e promover o crescimento vegetal (JAIZME-VeJA; AzCóN, 1995). Normalmente, a eficiência micorrízica está relacionada à quantidade de micélio externo formado no solo. Certos FMA podem possuir grande capacidade de colonizar o hospedeiro, porém a proporção de hifas externas (estruturas que permitem a maior absorção de nutrientes) varia muito entre as espécies de FMA (MARSCHNER, 1995).

No experimento em questão, G. clarumapresentou colonização micorrízica menor $(65,10 \%)$ e uma esporulação maior, ou seja, 254,1 esporos $(50 \mathrm{~mL})^{-1} \mathrm{de}$ solo, quando comparado a G. etunicatum com $85,21 \%$ de colonização micorrízica e esporulação de 171,50 esporos $(50 \mathrm{~mL})^{-1}$ de solo, mostrando inversão entre as duas variáveis. Situação semelhante foi demonstrada por BoRDIN (2002), na micorrização de tomateiros, obtendo maior colonização micorrízica com G. clarum $(63,28 \%)$ em comparação com Gigaspora margarita $(57,48 \%)$. Entretanto, esse autor obteve maior esporulação com G. margarita $\left(247,21\right.$ esporos.100 $\mathrm{g}^{-1}$ de solo seco) do que com G. clarum (15,65 esporos.100 g-1 de solo seco). Portanto, tanto os dados obtidos no experimento em questão, quanto os demonstrados por BORDIN (2002), corroboram com o que foi apresentado por DoudS JUNIOR; SCHENCK (1990), ou seja, em razão das condições tanto dos simbiontes como ambientais, a colonização e a densidade de esporos não são dependentes um do outro, embora se entenda que possam estar relacionados. Isto também foi demonstrado em experimentos onde se utilizaram diferentes concentrações de nutrientes na micorrização de Paspalum notatum por três FMA (Gigasporamargarita, Acaulospora longula e Glomus intraradices). Os resultados revelaram que a colonização e a densidade de esporos não são dependentes um do outro, de acordo com o simbionte e a concentração de nutrientes utilizados. Da mesma forma, Schubert et al. (1988) não observaram correlação entre densidade de esporos de FMA na rizosfera e a colonização de raízes em videiras. Deacordo com o fungo considerado, a resposta da planta pode sofrer alterações, porém seu potencial de resposta à colonização parece estar ligado à herança genética, ou seja, relacionado às características morfológicas, fisiológicas ou fenológicas do hospedeiro, que controlam a demanda e o suprimento de fósforo e, desta forma, o grau de dependência da planta (KoIDE, 1991). Aspectos da relação fungo-planta devem ser considerados para o estabelecimento da simbiose micorrízica, uma vez que efeitos da variação genotípica sobre a colonização têm sido relatados em grande número de espécies de plantas (GIANINAZZIPEARson, 1996).

Os dois FMA utilizados neste experimento foram também avaliados por SiLvAet al.(1998) na micorrização do urucuzeiro (Bixa orellana L.), junto com dois outros FMA, quais sejam, Gigaspora margarita e Scutellospora heterogama. Em relação ao número de esporos $/ 50 \mathrm{~cm}^{3}$ de solo foram constatadas diferenças significativas, sendo os maiores valores encontrados nos tratamentos com inoculação de G. clarum e G. margarita. Quanto à colonização micorrízica, os resultados também diferiram significativamente, porém os maiores resultados foram obtidos paraG.clarum eS.heterogama. Nestecaso, G. clarum foi o endófito mais eficiente, restando o terceirolugar para G. etunicatum, tantona variável esporulação quanto na colonização micorrízica. Esses autores verificaram ainda que todos os FMA não diferiram significativamente entre si e em relação à testemunha sem inoculação, nas variáveis altura, diâmetro à altura do colo e peso seco da parte aérea. 
Tabela 1 - Altura da planta (AP), produção média de matéria fresca radicular (MFR), produção média de matéria seca da parte aérea (MSPA), colonização radicular (CR) e esporulação (E) na presença e na ausência deGlomus clarume Glomus etunicatum em plantas de alecrim (média de 16 repetições).

\begin{tabular}{|c|c|c|c|c|c|}
\hline & $\mathrm{AP}(\mathrm{cm})$ & MFR (g/vaso) & MSPA (g/vaso) & CR (\%) & $\begin{array}{c}\mathrm{E}\left(\mathrm{n}^{\circ} \text { de esporos } /\right. \\
50 \mathrm{~mL} \text { solo })\end{array}$ \\
\hline Glomus clarum & $19,28 \mathrm{a}$ & $1,14 \mathrm{a}$ & $1,12 \mathrm{a}$ & $65,1 \mathrm{~b}$ & 254,1 a \\
\hline Glomus etunicatum & $15,53 \mathrm{~b}$ & $0,94 \mathrm{a}$ & $0,67 \mathrm{~b}$ & $85,21 \mathrm{a}$ & $171,50 \mathrm{~b}$ \\
\hline Testemunha & $15,31 \mathrm{~b}$ & $0,47 \mathrm{~b}$ & $0,74 \mathrm{~b}$ & $0,00 \mathrm{c}$ & $0,00 \mathrm{c}$ \\
\hline C.V. (\%) & 23,67 & 47,19 & 29,00 & 26,21 & 16,20 \\
\hline
\end{tabular}

Médias seguidas da mesma letra nas colunas não diferem significativamente entre si (Tukey, 5\%).

Para efeito de análise, os dados de colonização e esporulação foram transformados em arco seno $\sqrt{x / 100}$ e $\sqrt{x+0,5}$, respectivamente.

Tabela 2 - Altura da planta (AP), produção média de matéria fresca radicular (MFR), produção média de matéria seca da parte aérea (MSPA), colonização radicular (CR) e esporulação (E) na presença e na ausência deGlomus clarume Glomus etunicatum em plantas de manjericão (média de 12 repetições).

\begin{tabular}{lccccc}
\hline & AP (cm) & MFR (g/vaso) & MSPA (g/vaso) & CR (\%) & $\begin{array}{c}\text { E (n de esporos/ } \\
50 \mathrm{~mL} \text { solo) }\end{array}$ \\
\hline Glomus clarum & $7,26 \mathrm{a}$ & $2,54 \mathrm{a}$ & $0,56 \mathrm{a}$ & $79,72 \mathrm{a}$ & $345,50 \mathrm{a}$ \\
Glomus etunicatum & $5,79 \mathrm{~b}$ & $1,32 \mathrm{~b}$ & $0,29 \mathrm{~b}$ & $61,11 \mathrm{~b}$ & $176,33 \mathrm{~b}$ \\
Testemunha & $4,99 \mathrm{~b}$ & $0,71 \mathrm{~b}$ & $0,29 \mathrm{~b}$ & $0,00 \mathrm{c}$ & $0,00 \mathrm{c}$ \\
\hline C.V. $(\%)$ & 23,24 & 43,14 & 45,60 & 17,49 & 9,41 \\
\hline
\end{tabular}

Médias seguidas da mesma letra nas colunas não diferem significativamente entre si (Tukey, 5\%).

Para efeito de análise, os dados de colonização e esporulação foram transformados em arco seno $\sqrt{x / 100}$ e $\sqrt{x+0,5}$, respectivamente.

Na Tabela 2 estão expressos os dados relativos à micorrização das plantas de manjericão. Em relação a todas as variáveis analisadas, G. clarum diferiu do controle e de G. etunicatum apresentando 45,49\% em AP, 257,75\% em MFRe $93,10 \%$ em MSPA, quando comparado ao controle. Por outro lado, G. etunicatum foi semelhante ao tratamento controle em todas as variáveis, exceto para colonização micorrízica $(61,11 \%)$ e esporulação de 176,33 esporos $(50 \mathrm{~mL})^{-1}$ de solo. Portanto, G. clarum foi mais eficiente do queG. etunicatum na micorrização do manjericão.

A eficiência da simbiose micorrízica está relacionada com os fatores edafoclimáticos e aspectos da relação fungo-planta, ou seja, dependendo da espécie de fungo utilizada e das condições do meio ambiente, a eficiência da simbiose planta/FMA também varia (Powell;B AGYaraj, 1984;S Mith; GianinazZIPerson, 1988; Allen, 1991; Costa et al., 2001; CavalCANTEet al., 2002a; CAVALCANTE et al., 2002b). G. clarum e G. etunicatum apresentaram comportamento semelhante àquele mostrado por FreIT As etal. (2004); esses pesquisadores utilizaram Glomus clarum, Gigaspora margarita, Glomus etunicatum eAcaulosporascrobiculata na micorrização de Mentha arvensis L., empregando quatro dosagens diferentes de fósforo. Na ausência de adubação fosfatada, obtiveram maior produção de matéria fresca da parte aérea nos tratamentos com G. clarum eG. margarita (207 e 198\%, respectivamente), em relação ao tratamento controle. Por outrolado, G. etunicatum eA. scrobiculata foram menos eficientes em promover o crescimento das plantas em relação às outras duas espécies. Entretanto, esses autores relacionam o comportamento diferenciado de cada FMA de acordo com a quantidade de $\mathrm{P}$ aplicada no solo. Silveira et al. (2002), estudando o efeito de seis FMA (entre elas G. clarum e G. etunicatum) sobre o desenvolvimento vegetativo de plantas de abacateiro (Persea sp.), nas fases de porta-enxerto, de muda enxertada e de muda no pomar, verificaram que a influência desses FMA é variável de acordo com a espécie do endófito envolvido. Esses autores relatam ainda que os FMA G. etunicatum, G. clarum, S. heterogama e A. scrobiculata propiciaram melhor desenvolvimento vegetativo desde o período de formação das mudas até o transplante ao campo e também após essa fase.

Como demonstrado nos experimentos realizados com o alecrim e manjericão, os FMA podem apresentar comportamentos diferentes em relação às variá- 
veis avaliadas, de acordo com o hospedeiro utilizado. $\mathrm{Na}$ avaliação geral, G. clarum foi mais eficiente do que G. etunicatum; entretanto, no caso do alecrim, G. etunicatum apresentou maior CR do que G. clarum, enquanto que para MFR não houve diferença entre as duas micorrizas utilizadas.

\section{CONCLUSÕES}

Com base nos resultados obtidos, conclui-se que tanto G. etunicatum quanto G. clarum são eficientes na colonização de raízes de plantas de alecrim e manjericão e do substrato de crescimento das plantas utilizado, embora G. clarum mostra-se mais eficiente do que G. etunicatum para o manjericão. Comparado às plantas testemunha, G. clarum proporcionou ao manjericão aumentos de $45,49 \%$ na altura das plantas (AP) e 93,10\% na produção de matéria seca da parte aérea (MSPA).

\section{REFERÊNCIAS}

ABBOTT, L.K.; ROBSON, A.D. The effect of VA mycorrhizae on plant growth. In: POWELL, L.; BAGYARAJ, D.J. (Ed.). VA mycorrhiza. Boca Raton: CRC Press, 1984. p.113-130.

ALLEN, M.F. The ecology of mycorrhizae. San Diego: Cambridge University Press, 1991. 184p.

ANTONIOLLI, Z.I.; KAMINSKI, J. Micorizas: revisão bibliográfica. Ciência Rural, Santa Maria, v.21, n.3, p.441-455, 1991.

BORDIN, S.S. Interação fungos micorrízicos arbusculares e Meloidogyne incognita, em plantas de tomateiro e pimentão. 2002. 70f. Tese (Doutorado em Agronomia) - Faculdade de Ciências Agronômicas, Universidade Estadual Paulista, Botucatu, 2002.

BRESSAN, W.; SIQUEIRA, J.O.; VASCONCELLOS, C.A.; PURCINO, A.C.P. Fungos micorrízicos e fósforo, no crescimento, nos teores de nutrientes e na produção do sorgo e soja consorciados. Pesquisa Agropecuária Brasileira, v.36, p.315-323, 2001.

CAMPRUBI, A.; ESTAUN, V.; CALVET, C.; PERA, J. Infectivity and effectivity of Glomus mosseae mycorrhizae in 4 different species of medicinal-plants. Symbiosis, v.9, n.1/3, p.305-307, 1991.

CARVALHO, W.A.; ESPÍNDOLA, C.R.; PACCOLA, A.A. Levantamento de solos da Fazenda Lageado Estação Experimental Presidente Médici. Botucatu: Faculdade de Ci\}encias Agronômicas, UNESP, 1983. v.1, 95p. (Boletim Científico, 1).
CAVALCANTE, U.M.T.; MAIA, L.C.; COSTA, C.M.C.; CAVALCANTE, A.T.; SANTOS, V.F. Efeito de fungos micorrízicos arbusculares, da adubação fosfatada e da esterilização do solo no crescimento de mudas de maracujazeiro amarelo. Revista Brasileira de Ciência do Solo, v.26, p.1099-1106, 2002a.

CAVALCANTE, U.M.T.; MAIA, L.C.; COSTA, C.M.C.; SANTOS, V.F. Influência da densidade de fungos micorrízicos arbusculares na produção de mudas de maracujazeiro-amarelo. Pesquisa Agropecuária Brasileira, v.37, p.643-649, 2002b.

COSTA, C.M.C.; MAIA, L.C.; CAVALCANTE, U.M.T.; NOGUEIRA, J.M.C. Influência de fungos micorrízicos arbusculares sobre o crescimento de dois genótipos de aceroleira (Malpighia emarginata D.C.). Pesquisa Agropecuária Brasileira, v.36, p.893-901, 2001.

DOUDS JUNIOR, D.D.; SCHENCK, N.C.

Relationship of colonization and sporulation by VA mycorrhizal fungi to plant nutrient and carbohydrate contents. New Phytologist, v.116, p.621627, 1990.

FREITAS, M.S.M.; MARTINS, M.A.; VIEIRA, I.J.C. Produção e qualidade de óleos essenciais de Mentha arvensis em resposta à inoculação de fungos micorrízicos arbusculares. Pesquisa Agropecuária Brasileira, v.39, n.9, p.887-894, 2004.

GERDEMANN, J.W.; NICOLSON, T.H. Spores of mycorrhizal Endogone species extracted from soil by wet sieving and decanting. Transactions of the British Mycological Society, v.46, n.2, p.235-244, 1963.

GIANINAZZI-PEARSON, V. Plant cell response to arbuscular mycorrhizal fungi: getting to the roots of the symbiosis. Plant Cell, v.8, p.1871-1883, 1996.

GIOVANNETTI, M.; MOSSE, B. An evaluation of techniques for measuring vesicular-arbuscular mycorrhiza infections in roots. New Phytologist, v.84, p.489-500, 1980.

GUPTA, M.L.; PRASAD, A.; RAM, M.; KUMAR, S. Effect of the vesicular-arbuscular mycorrhizal (VAM) fungus Glomus fasciculatum on the essential oil yield related characters and nutrient acquisition in the crops of different cultivars of menthol mint (Mentha arvensis) under field conditions. Bioresource Technology, v.81, p.77-79, 2002.

JAIZME-VEJA, M.C.; AZCON, R. Responses of some tropical and subtropical cultures to endomycorrhizal fungi. Mycorrhiza, v.5, p.213-217, 1995.

JENKINS, W.R. A rapid centrifugal-flotation technique for separating nematodes from soil. Plant Disease Reports, v.48, p.692, 1964. 
KAPOOR, R.; GIRI, B.; MUKERJI, K.G. Mycorrhization of coriander (Coriandrum sativum L.) to enhande the concentration and quality of essencial oil. Journal of the Science of Food and Agriculture, v.82, n.4, p.339-342, 2002a.

KAPOOR, R.; GIRI, B.; MUKERJI, K.G. Glomus macrocarpum: a potencial bioinoculant to improve essencial oil quality and concentration in Dill (Anethum graveolens L.) and Carum (Trachyspermum ammmi (Linn.) Sprague). World Journal of Microbiology and Biotechnology, v.18, p.459-463, $2002 b$.

KOIDE, R.T. Nutrient supply, nutrient demand and plant response to mycorrhizal infection. New Phytologist, v.113, n.3, p.365-386, 1991.

MARSCHNER, H. Mineral nutrition of higher plants. Cambridge: Academic Press, 1995. 889p.

PAULA, M.A.; SIQUEIRA, J.O. Efeitos da umidade do solo sobre a simbiose endomicorrízica em soja. II. Crescimento, nutrição e relação água-planta. Revista Brasileira de Ciência do Solo, v.11, p.289-293, 1987.

PHILLIPS, J.M.; HAYMAN, D.S. Improved procedures for clearing and staining parasitic and vesiculararbuscular mycorrhizal fungi for rapid assessment of infection. Transactions of the British Mycological Society, v.55, p.158-161, 1970.

POWELL, C.L.; BAGYARAJ, D.J. VA mycorrhiza. Boca Raton: CRC Press, 1984. 234p.

RAIJ, B. VAN; ANDRADE, J.C.; CANTARELLA, H.; QUAGGIO, J.A. Análise química para avaliação da fertilidade de solos tropicais. Campinas: Instituto Agronômico, 2001. 285p.

SANCHEZ-BLANCO, M.J.; FERRANDEZ, T.; MORALES, M.A.; MORTE, A.; ALARCON, J.J. Variations in water status, gás exchange, and growth in Rosmarinus officinalis plants infected with Glomus deserticola under drought conditions. Journal of Plant Physiology, v.161, n.6, p.675$682,2004$.

SARRUGE, J.R. Soluções nutritivas. Summa Phytopathologica, v.1, n.3, p.231-233, 1975.
SCHUBERT, A.; CAMMMARATA, S.; EYNARD, I. Growth and root colonization of grapevines inoculated with different mycorrhizal endophytes. Hort Science, v.23, n.2, p.302-302, 1988.

SILVA, E.M.R. da; SUDO, A.; ALMEIDA, D.L. de; MATOS, R.M.B.; PEREIRA, M.G.; BOVI, M.L.A.; MACHADO, C.T.T. Ocorrência e efetividade de fungos micorrízicos em plantas cultivadas. Seropédica: Embrapa Agrobiologia, 1998. 25p. (Embrapa-CNPAB. Documentos, 83).

SILVEIRA, A.P.D. Micorrizas. In: CARDOSO, E.J.B.N.; TSAI, S.M.; NEVES, M.C.P. (Coord.). Microbiologia do solo. Campinas: Sociedade Brasileira de Ciência do Solo, 1992. p.257-282.

SILVEIRA, S.V.; SOUZA, P.V.D.; KOLLER, O.C. Influência de fungos micorrízicos arbusculares sobre o desenvolvimento vegetativo de porta-enxertos de abacateiro. Pesquisa Agropecuária Brasileira, v.37, p.303-309, 2002.

SIQUEIRA, J.O. Micorrizas: forma e função. In: REUNIÃO BRASILEIRA SOBRE MICORRIZAS, 1., 1986, Lavras, MG. Resumos. Lavras: Escola Superior de Agricultura de Lavras, 1986.

SMITH, S.E.; GIANINAZZI-PEARSON, J. Physiological interactions between symbiosis in vesicular-arbuscular mycorrhizal plants. Annual Review of Plant Physiology and Plant Molecular Biology, v.39, p.221-224, 1988. SMITH, S.E.; READ, D.J. Mycorrhizal symbiosis. 2nd ed. London: Academic Press, 1997. 605p.

SNEDECOR, G.W.E.; COCHRAN, W.C. Statistical Methods. 6th.ed., 5 reimp. Iwoa State Univ. Press, 1972. $325 \mathrm{p}$.

ZAMBOLIM, L.; SIQUEIRA, J.O. Importância e potencial das associações micorrízicas para a agricultura. Belo Horizonte: EPAMIG, 1985. 36p.

Recebido em 26/1/07

Aceito em 13/3/08 